\section{Commentary: What do we still have to learn from surgery?}

\author{
Igor Belluschi, MD, ${ }^{\mathrm{a}}$ Mattia Glauber, $\mathrm{MD},{ }^{\mathrm{b}}$ and \\ Antonio Miceli, $\mathrm{MD}^{\mathrm{b}}$
}

The mitral valve apparatus represents an example of how nature designs a perfect, harmonic, and functional body structure, like a fascinating and solid renaissance cathedral. However, this beautiful architecture can be damaged by external events, such as atmospheric agents and earthquakes, requiring conservative restoration whenever possible. Similarly, the effect of different diseases, such as myocardial infarction, myocarditis, or eccentric hypertrophy, may damage the whole mitral valve architecture, requiring interventions. Functional mitral regurgitation (FMR) is the result of the posterior and lateral dislocation of papillary muscles, which leads to apical leaflet tethering and lack of coaptation. ${ }^{1}$ When the geometry is fully distorted, repair strategies cannot guarantee optimal and durable results, and valve replacement may remain the only available solution. ${ }^{2}$ On the contrary, an undersized annuloplasty can force coaptation and decreases regurgitant jet in less-challenging anatomies. The advantage of valve repair over replacement in the context of ischemic mitral regurgitation has been long debated, but previous series showed that repair is associated with lower perioperative mortality, despite an increased risk of mitral regurgitation recurrence. ${ }^{3}$ The high rate of repair failure could be related to the subvalvular mitral dysfunction, which is not often addressed, leaving tension on the leaflet because of left ventricular enlargement. ${ }^{4}$ Furthermore, undersized annuloplasty also could result in increased transvalvular gradient, due to extreme tethering, which paradoxically limit leaflet excursion. ${ }^{5}$ In this setting, several surgical techniques have

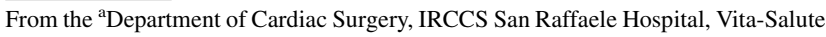
San Raffaele University; and 'Department of Cardiac Surgery, Sant'Ambrogio Hospital, Milan, Italy.

Disclosures: The authors reported no conflicts of interest.

The Journal policy requires editors and reviewers to disclose conflicts of interest and to decline handling or reviewing manuscripts for which they may have a conflict of interest. The editors and reviewers of this article have no conflicts of interest.

Received for publication June 13, 2021; revisions received June 13, 2021; accepted for publication June 18, 2021; available ahead of print July 13, 2021.

Address for reprints: Antonio Miceli, MD, Minimally Invasive Cardiac Department, Istituto Clinico Sant'Ambrogio, Via LG Faravelli 16, 20149 Milano, Italy (E-mail: Antoniomiceli79@alice.it).

JTCVS Open 2021;7:109-10

2666-2736

Copyright (c) 2021 The Author(s). Published by Elsevier Inc. on behalf of The American Association for Thoracic Surgery. This is an open access article under the CC BY-NC-ND license (http://creativecommons.org/licenses/by-nc-nd/4.0/).

https://doi.org/10.1016/j.xjon.2021.06.014
}

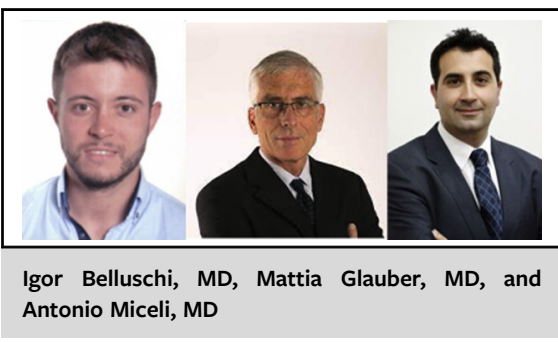

CENTRAL MESSAGE

Biomechanical analysis explains the dynamics beyond papillary muscle approximation as an emerging treatment for functional mitral regurgitation.

been proposed: chordal transection, anterior leaflet augmentation, relocation, and approximation of the papillary muscles. The latter, which consists in approximating the tips of 2 papillary muscles with pledget sutures, has shown promising mid-term results, especially when compared with annuloplasty alone. ${ }^{6,7}$ Its aim is to relief the tethering forces on the leaflets and restores coaptation geometry. However, no data on the mechanics of such treated valve have yet been reported. So, what are we missing to improve FMR repairability?

In this issue of the Journal, Zhan-Moodie and colleagues $^{8}$ provided an ex vivo model of FMR, combining papillary muscle approximation and 2 complete annuloplasty rings (true dimension $30 \mathrm{~mm}$ vs undersized $26 \mathrm{~mm}$ ). The most significant results were obtained when papillary muscle approximation was associated to the undersized ring, showing lower regurgitant fraction (from a mean of $16 \%$ to $4 \%$ ), lower tenting area $\left(83-22 \mathrm{~mm}^{2}\right)$, lower height (11-4 mm), and augmented coaptation length. Leaflet mobility was restored as well, due to an increased leaflet excursion angles and a reduction of chordal forces. Furthermore, this simple procedure on the papillary muscles also could allow leaflet mobilization also associated with larger annular rings. As a result, authors suggest that rings of larger sizes may be used if combined to muscle approximation, thus avoiding the risk of stenosis linked to undersizing. However, major drawbacks of this model are the choice of isolated swine healthy mitral valves and the lack of either concomitant ventricle dynamics and pathologic fibrotic tissue. For the first time, this study provides biomechanical data on papillary muscle approximation in association with annuloplasty, showing relief of tethering forces on leaflet during systole and better coaptation. Whilst 
surgeons are still debating about the treatment of choice, the COAPT $^{9}$ (Cardiovascular Outcomes Assessment of the MitraClip Percutaneous Therapy for Heart Failure Patients with Functional Mitral Regurgitation) trial has easily demonstrated that percutaneous repair can treat FMR. ${ }^{8}$

Nevertheless, the translational analysis by Zhan-Moodie and colleagues is evidence that we have still something to learn from surgery. However, not all questions have been answered yet: will there be a role for a percutaneous papillary muscle approximation?

\section{References}

1. Miceli A. Commentary: a device for the whole mitral valve apparatus. $J$ Thorac Cardiovasc Surg. 2021;161:959-60.

2. Kron IL, Hung J, Overbey JR, Bouchard D, Gelijns AC, Moskowitz AJ, et al. Predicting recurrent mitral regurgitation after mitral valve repair for severe ischemic mitral regurgitation. J Thorac Cardiovasc Surg. 2015;149: 752-61.e1.
3. Gillinov AM, Wierup PN, Blackstone EH, Bishay ES, Cosgrove DM, White J, et al. Is repair preferable to replacement for ischemic mitral regurgitation? $J$ Thorac Cardiovasc Surg. 2001;122:1125-41.

4. Piérard LA, Carabello BA. Ischaemic mitral regurgitation: pathophysiology, outcomes and the conundrum of treatment. Eur Heart J. 2010;31:2996-3005.

5. Kawamoto N, Fujita T, Fukushima S, Shimahara Y, Kume Y, Matsumoto Y, et al. Functional mitral stenosis after mitral valve repair for type II dysfunction: determinants and impacts on long-term outcome. Eur J Cardiothorac Surg. 2018;54: 453-9.

6. Wakasa S, Kubota S, Shingu Y, Ooka T, Tachibana T, Matsui Y. The extent of papillary muscle approximation affects mortality and durability of mitral valve repair for ischemic mitral regurgitation. J Cardiothorac Surg. 2014;9:98.

7. Meco M, Lio A, Montisci A, Panisi P, Ferrarini M, Miceli A, et al. Meta-analysis of results of subvalvular repair for severe ischemic mitral regurgitation. J Card Surg. 2020;35:886-96.

8. Zhan-Moodie S, Xu D, Suresh KS, He Q, Onohara D, Kalra K, et al. Papillary muscle approximation reduces systolic tethering forces and improves mitral valve closure in the repair of functional mitral regurgitation. J Thorac Cardiovasc Surg Open. 2021;7:91-104.

9. Stone GW, Lindenfeld J, Abraham WT, Kar S, Lim DS, Mishell JM, et al. Transcatheter mitral-valve repair in patients with heart failure. $N$ Engl J Med. 2018;379: 2307-18. 